\title{
IDEOLOGÍA Y PODER EN EL ARTE RUPESTRE PREHISTÓRICO GALLEGO
}

\author{
por
}

\author{
J.M. VÁZQUEZ VARELA
}

$\mathrm{El}$ arte rupestre gallego es rico en temas abstractos y poco narrativo, por lo que no resulta fácil reconstruir aspectos de la sociedad que lo produjo y en especial de su vida cotidiana ${ }^{1}$.

A pesar de estas dificultades es posible obtener información valiosa sobre algunos temas a través del estudio de los utensilios representados y de las escenas especialmente de aquellas donde aparece la figura humana. La información obtenida para su correcta interpretación ha de ser contrastada con los otros elementos arqueológicos disponibles, tumbas, artefactos cerámicos, líticos y metálicos y restos de plantas y animales pues a menudo las representaciones artísticas no son un reflejo lineal de la realidad sino que por el contrario privilegian determinados aspectos de la cultura. Esta distorsión de lo real por un lado podemos considerarla negativa pues aumenta las dificultades ya de por si grandes de los petroglifos para hacer interpretaciones seguras de la vida en el pasado pero por otro el hecho de que la visión de la realidad esté deformada nos abre la puerta a

${ }^{1}$ García Alén, A. y Peña Santos, A. de la: Grabados rupestres de la provincia de Pontevedra. La Coruña, 1980.

Peña Santos, A. de la y Vázquez Varela, J.M.: Los petroglifos gallegos. La Coruña, 1979.

Vázquez Varela, J.M.: Os petroglifos de Galicia. Santiago, 1990.

"CUADERNOS DE ESTUDIOS GALLEGOS", Tomo XXXIX, Fascículo 104, Santiago 1991. 

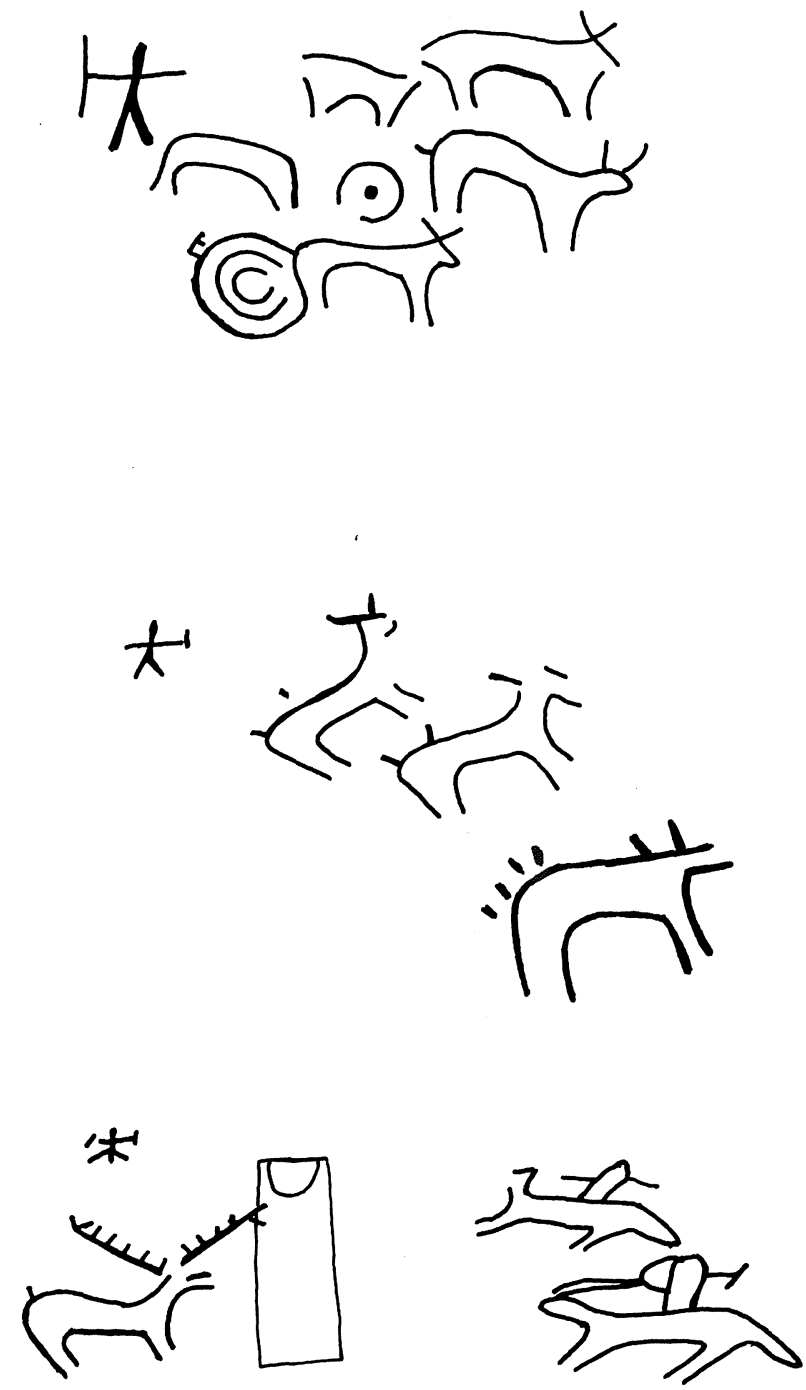

En la parte superior: Escena de caza o pastoreo en A Pedra da Bullosa, Campo Lameiro, Pontevedra.

En el centro: Escena de Caza de A Pedra das Ferraduras.

En la parte inferior: A la izquierda figuras del sector central de A Pedra das Ferradura Idolo-cilindro, ciervo y hombre.

A la derecha. Jinetes de A Laxe dos Cabalos, Paredes, Campo Lameiro. Pontevedra.

"CUADERNOS DE ESTUDIOS GALLEGOS", Tomo XXXIX, Fascículo 104, Santiago 1991 
otra dimensión del conocimiento. Se trata de profundizar, a partir del análisis de las causas de este fenómeno, en aspectos ideológicos de este mundo que de otra forma serían muy difíciles de percibir.

La investigación debe centrarse en dos puntos: Primero en el análisis de los objetos representados y del contexto en que hacen su aparición. El segundo objetivo es la interpretación de las no muy numerosas escenas.

No son muchos los objetos susceptibles de ser interpretados con seguridad. Dentro de estos podemos incluir armas tales como puñales de diferentes tipos y alabardas, escudos, quizá algún hacha. Dentro de aquellos cuyo identificación es más difícil cabe señalar los que están representados por un trazo recto en las manos de las figuras humanas que pueden ser lanzas, azagayas, palos o bastones. Estos mismos trazos en el caso de que estén clavados en el cuerpo de un animal tal como se aprecia en las escenas de caza pueden ser azagayas, lanzas o flechas. La correcta interpretación de otras figuras ya no es posible en el estado actual de la investigación.

Si se comparan los objetos representados con los de uso cotidiano de las épocas a las que corresponden encontramos una gran selección que excluye a la inmensa mayoría de los artefactos habitualmente empleados y que se centra en un número muy determinado que tienen un carácter excepcional en cuanto a su abundancia y significación tal como es el caso de las armas metálicas y de los ídolos-cilindro. Por ello podemos llegar a la conclusión de que en este arte se reflejan aquellos elementos materiales que tienen un gran valor social indicativos de la ideología secular, el caso de las armas que reflejan el prestigio de la posesión de elementos metálicos y de lo bélico, y de la religiosa, los ídolos-cilindro indicativos de la dimensión funeraria de lo religioso en el período megalítico.

De acuerdo con lo anterior podemos considerar que la sociedad de la época valoraba los productos metálicos como signo de estatus y que la actividad bélica gozaba de especial prestigio. Puede que ello indique el elevado papel social de los grupos que detentaban el acceso a las armas y la práctica de la guerra.

La representación de los ídolos refleja la preocupación por la religión y la muerte que requiere complejos rituales y que debió estar vinculada a una mitología ampliamente extendida por las zonas meridional y occidental de la Península Ibérica.

Las escenas ofrecen una información muy interesante aunque limitada a causa de su escasez o de su carácter poco narrativo. Los temas representados son muy genéricos y reiterativos pues prácticamente se reducen a escenas de monta y/o doma de caballos y a cacerías de ciervos.

Algunas de estas últimas pudieran interpretarse como escenas de pastoreo donde el hombre lleva un palo largo con el que controla los movimientos del ganado. 
De nuevo nos encontramos con la ausencia casi total de las actividades más frecuentes de la vida cotidiana pues no se aprecian prácticas agrícolas o ganaderas. Esto podría interpretarse en el sentido de que en el arte solo aparecen actividades de prestigio social, la caza y la monta, aunque está ausente la guerra que pudiera estar implícitamente representada si es correcta la interpretación de la presencia de las armas y no de unas cualesquiera sino precisamente de las más prestigiosas.

Parece de acuerdo con lo expuesto que los autores del arte rupestre grabaron fundamentalmente objetos y actividades de prestigio social en el que reflejan el valor de la metalurgia, de las armas, de la monta y de la caza. Así el arte resulta poco narrativo y dotado de un fuerte valor simbólico en el que se refleja la ideología secular y la religiosa en tanto en cuanto tenga valor esta diferencia para las sociedades protohistóricas.

Las actividades más frecuentes de la vida cotidiana están ausentes salvo las posibles escenas de pastoreo, práctica que indudablemente existió pero cuya importancia en el total de la economía no conocemos pues esta era compleja y tenía una sólida base agrícola, recolectora, metalúrgica y de aprovechamiento de los recursos marinos que permitía el desarrollo de intercambios de diferentes productos tales como los mineros y los metálicos ${ }^{2}$.

Puede que el pastoreo de los grandes animales como los bóvidos fuese también una actividad socialmente prestigiosa en cuyo caso se refuerza la conclusión anterior sobre el reflejo de aquellas actividades que tenían un papel social importante.

De la economía sólo queda indicada la actividad metalúrgica, reflejada en la presencia de las armas, la ganadería en las posibles escenas de pastoreo y en las de equitación así como la caza de ciervos.

Sobre los aspectos sociales cabe destacar la figura del guerrero que ostenta la espada, el cazador, los posibles pastores y los jinetes. Si bien no se puede precisar el sexo de la mayoría de las figuras humanas es muy probable que todas ellas sean de hombres si nos atenemos al hecho de que los que tienen algún atributo sexual son varones y que los datos de otras culturas de la época y de las primitivas actuales señalan que en la mayor parte de ellas las actividades citadas, guerra, metalurgia, pastoreo y equitación son propias de los hombres. Si esto fuese así podríamos ir más lejos y decir que en los petroglifos se representa el orden social de una comunidad donde el poder se concentra en gran medida en manos de los hombres.

Los datos arqueológicos a pesar de su ambigüedad no contradicen esta visión que podemos atribuir de un modo especial a la sociedad de la Edad

2 Vázquez Varela, J.M.: Las raices de Galicia. Santiago, 1980. 


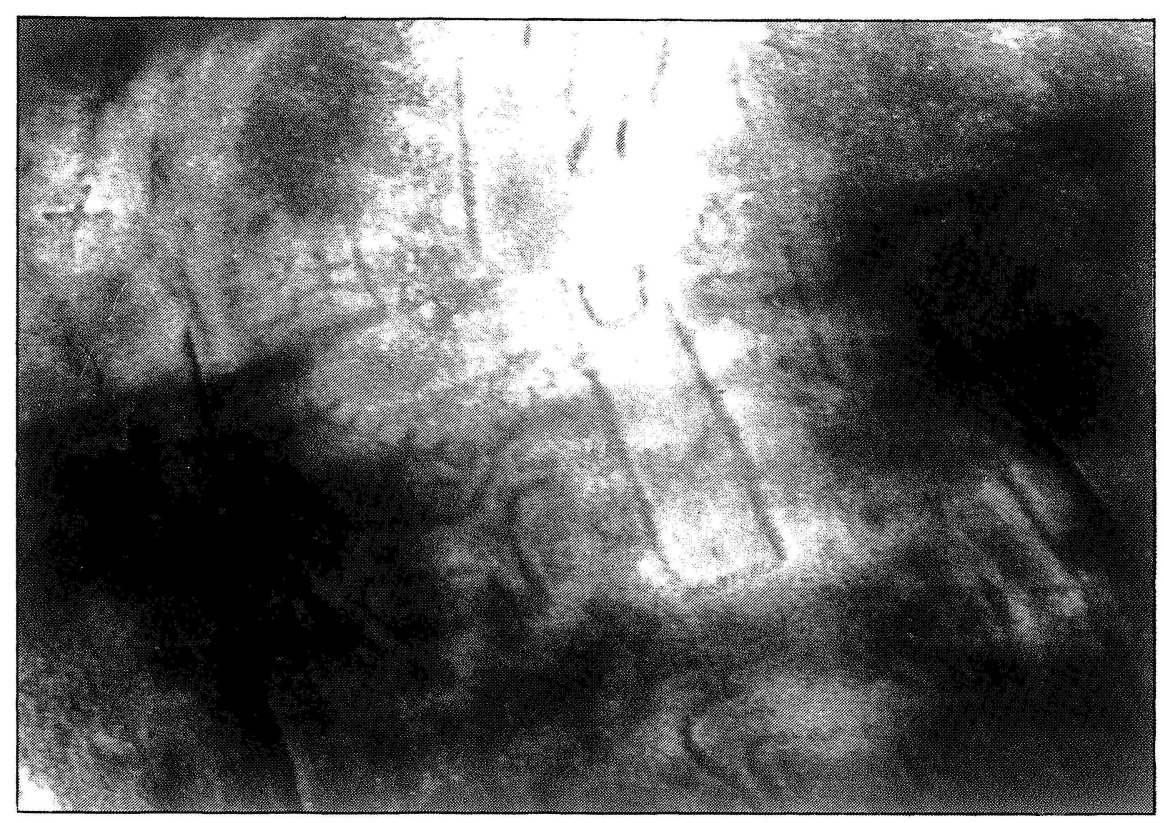

Área central de A Pedra das Ferraduras, Fentans, Cotobade, Pontevedra. Ídolocilíndrico al que se superpone un ciervo. A la izquierda un hombre porta útiles largos. En la parte superior hay una figura humana que sostiene un puñal de tamaño desproporcionado y un escudo redondo.

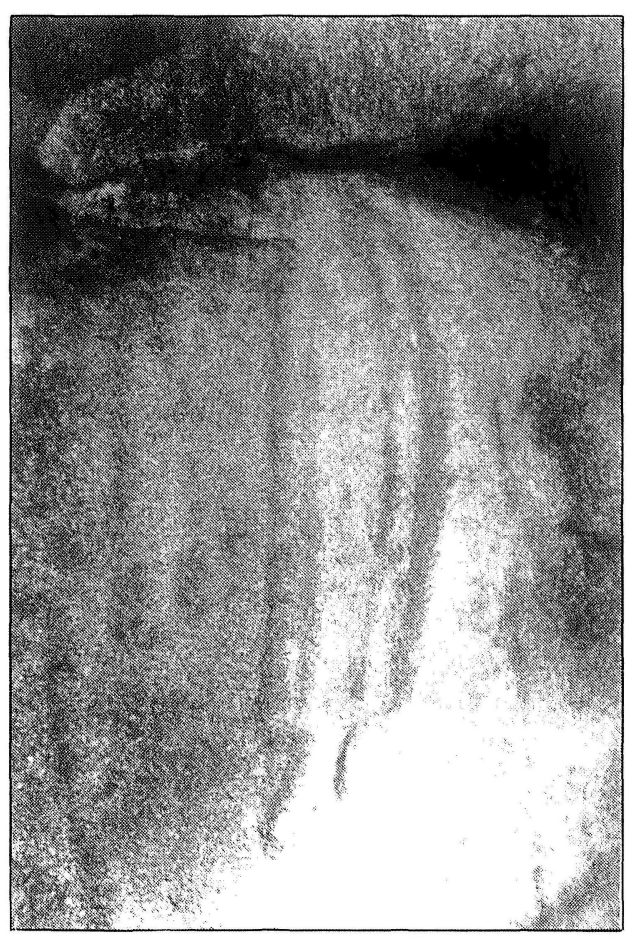

Parte superior de la cara inclinada de la Pedra das Ferraduras. Una figura humana porta un escudo y un puñal. A la izquierda hay otro puñal más pequeño. 
del Bronce. Las dificultades de datación de las escenas impiden pronunciarse sobre estos aspectos en el mundo anterior que pudo haber sido diferente.

La presencia de escenas donde se reflejan actividades prestigiosas masculinas puede ser interpretada como expresión del mundo del varón, de su ideología y poder.

Estas ideas encajan bastante bien con lo que tradicionalmente se viene afirmando sobre las características básicas de la Edad del Bronce de Europa, reconstruida a partir de los datos procedentes de tumbas y poblados. Ir más allá y afirmar que en las escenas se refleja la mentalidad patriarcal del momento, como afirman numerosos autores hasta el punto de que esta opinión se ha convertido en un tópico, resulta aventurado.

La idea del patriarcado, formulación más extrema, o la de la existencia de numerosos rasgos patriarcales deriva en gran parte de la proyección sobre este mundo de la forma de vida que conocemos a través de la Iliada y la Odisea. El amplio conocimiento que de estas obras tenían los arqueólogos con buena formación clásica influyó de un modo consciente o inconsciente en la interpretación de la Edad del Bronce a imagen y semejanza de la epopeya griega.

Esta idea se ha visto reforzada al desvelarse la estructura de la sociedad indoeuropea a partir de la comparación, de las lenguas y culturas indoeuropeas. Dado que el modelo de esta sociedad es de corte patriarcal y que estos pueblos están presentes en mayor o menor grado en la Europa de la Edad del Bronce se extrapoló este sistema de organización a todos los pueblos de la Europa de esta época.

Si bien esta propuesta tiene aspectos valiosos ha sido excesivamente generalizada a la protohistoria, pues Europa en ese momento es un complejo mosaico de culturas en la que al lado de aspectos comunes a todas ellas existen una gran cantidad de manifestaciones peculiares de cada una, por lo que toda generalización excesiva resulta problemática.

Por otra parte cuando se habla de culturas patriarcales se plantea el auténtico significado del término que a menudo resulta demasiado impreciso o por el contrario excesivamente rígido para aplicarlo a una realidad cultural concreta.

Ante estos problemas metodológicos hay que actuar con cautela profundizando en el análisis de las cuestiones relacionadas con la epistemología y la semántica.

Las actividades masculinas de prestigio representadas en los grabados prehistóricos de Galicia al igual que otras semejantes, en otros conjuntos de arte protohistórico de la zona alpina y de los paises nórdicos, son propias tanto de sistemas sociales donde el varón controla el poder de un modo más o menos intenso, los sistemas patrilineales, que de otros donde 
es la mujer la que genera el linaje, posee la tierra y su residencia prematrimonial se convierte en el domicilio del matrimonio tal cual es el caso de los sistemas matrilineales.

La caza, la guerra y la equitación en la inmensa mayoría de las culturas conocidas a través de registro histórico y etnográfico y en las culturas prehistóricas, en las que los datos arqueológicos permiten conocer con claridad el diferente status y rol de los sexos, son actividades exclusivas de los hombres. Por esto no se pueden atribuir mecánicamente a un sistema de dominio social del varón este tipo de actividades ya que ocurren por igual en sociedades matrilineales y patrilineales.

El empleo del término patriarcal es aún más problemático como todo aquello que resulta demasiado genérico pues cuanto más abstracto es un concepto menos refleja la realidad.

La forma extrema de una sociedad patriarcal sería aquella en la que el varón detentase el poder a todos los niveles, linaje a través del padre, residencia patrilocal, potestad del hombre y su supremacía tanto en la esfera de lo público como en la de lo privado.

Existen y han existido sociedades muy próximas a este esquema teórico pero nunca en ellas el poder del varón es total ya que incluso cuando éste es grande hay cierto grado de control de la situación por parte de la mujer a través de mecanismos más o menos implícitos y sutiles. Estas parcelas de poder o este ejercicio del poder especializado dejan muy poco rastro en el registro arqueológico.

De acuerdo con esto el término patriarcal ha de ser manejado con prudencia y nunca usado para designar al total de las sociedades protohistóricas de Europa. Sería más correcto decir que es muy probable que el modelo social de algunas comunidades europeas era próximo al esquema teórico del patriarcado y que en otras el hombre ejercitaba la caza, la guerra, el manejo del arado y el pastoreo de grandes animales mientras que de la mayoría de ellas no sabemos nada seguro. De esta propuesta a la de generalizar la existencia de una hipotética organización patriarcal hay una buena diferencia.

La relativa frecuencia de la aparición de grabados de armas podría interpretarse como señal inequívoca de la importancia de la guerra como suele inferirse de las escenas donde aparecen combates o actividades marciales. Sin embargo hay que recordar que de acuerdo con los datos etnológicos e históricos la guerra en las sociedades primitivas tiene características muy peculiares que la diferencian claramente de la actividad bélica en los pueblos modernos más o menos industrializados. La guerra primitiva tiene mucho de actividad ritual vinculada con la búsqueda de prestigio y de status y con la iniciativa individual. A menudo los combates suelen ser más competiciones o juegos bélicos que auténticas batallas y

"CUADERNOS DE ESTUdIOS GALLEGOS", Tomo XXXIX, Fascículo 104, Santiago 1991. 
ocasionan un número muy reducido de víctimas. Esto no quita para que en ocasiones pueda haber verdaderas matanzas ${ }^{3}$. Pero en todo caso un estado constante de guerra con un elevado número de víctimas no es compatible con una economía de subsistencia y una población de reducido tamaño. Por eso las representaciones de armas en particular o de escenas bélicas en general a menudo no indican una situación real de guerra constante sino que solo son indicativas del prestigio de lo bélico y de una ideología en la que el aspecto marcial es interesante tal vez como legitimador del orden social.

De acuerdo con lo expuesto se puede concluir que el arte rupestre gallego, que en esto coincide con el levantino y el de los conjuntos de los Alpes italianos y franceses y de los países nórdicos, expresa una ideología en la que destaca el mundo del varón mediante la representación de escenas en las que éste ejecuta actividades de prestigio social tales como la caza, la guerra y alguna ocupación especial como la monta del caballo. Los grabados manifiestan la ideología del dominio social del hombre que se legitima en un arte al servicio del poder de sus autores. Esta propuesta que es una hipótesis que presenta cierto grado de coherencia, ¡la única seguridad que le queda al prehistoriador!, ha de ser contrastada con el material arqueológico en especial con los habitats, las tumbas y los depósitos. La poca información de la que disponemos para Galicia no la contradice. Para el caso de los grabados rupestres protohistóricos de la Europa continental también existe un cierto grado de concordancia entre el arte y el resto del material arqueológico. De todos modos sólo una serie de excavaciones en poblados y cementerios permitirá contrastar la interpretación esbozada y conocer su grado de fiabilidad.

\footnotetext{
${ }^{3}$ Brian Ferguson, R.: Warfare, Culture and Environment. London, 1984.
} 